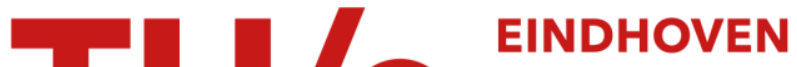 UNIVERSITY OF TECHNOLOGY
}

\section{Composite ultrafiltration membranes with tunable properties based on a self-assembling block copolymer/homopolymer system}

\author{
Citation for published version (APA): \\ Vriezekolk, E. J., Kudernac, T., de Vos, W. M., \& Nijmeijer, K. (2015). Composite ultrafiltration membranes with \\ tunable properties based on a self-assembling block copolymer/homopolymer system. Journal of Polymer \\ Science, Part B: Polymer Physics, 53(21), 1546-1558. https://doi.org/10.1002/polb.23795
}

DOI:

10.1002/polb.23795

Document status and date:

Published: 01/11/2015

\section{Document Version:}

Publisher's PDF, also known as Version of Record (includes final page, issue and volume numbers)

\section{Please check the document version of this publication:}

- A submitted manuscript is the version of the article upon submission and before peer-review. There can be important differences between the submitted version and the official published version of record. People interested in the research are advised to contact the author for the final version of the publication, or visit the DOI to the publisher's website.

- The final author version and the galley proof are versions of the publication after peer review.

- The final published version features the final layout of the paper including the volume, issue and page numbers.

Link to publication

\footnotetext{
General rights

- You may freely distribute the URL identifying the publication in the public portal. follow below link for the End User Agreement:

www.tue.nl/taverne

\section{Take down policy}

If you believe that this document breaches copyright please contact us at:

openaccess@tue.nl

providing details and we will investigate your claim.
}

Copyright and moral rights for the publications made accessible in the public portal are retained by the authors and/or other copyright owners and it is a condition of accessing publications that users recognise and abide by the legal requirements associated with these rights.

- Users may download and print one copy of any publication from the public portal for the purpose of private study or research.

- You may not further distribute the material or use it for any profit-making activity or commercial gain

If the publication is distributed under the terms of Article $25 \mathrm{fa}$ of the Dutch Copyright Act, indicated by the "Taverne" license above, please 


\title{
Composite Ultrafiltration Membranes with Tunable Properties Based on a Self-Assembling Block Copolymer/Homopolymer System
}

\author{
Erik J. Vriezekolk, ${ }^{1}$ Tibor Kudernac, ${ }^{2}$ Wiebe M. de Vos, ${ }^{1}$ Kitty Nijmeijer ${ }^{1}$ \\ ${ }^{1}$ Membrane Science and Technology, MESA + Institute for Nanotechnology, University of Twente, \\ P.O. Box 217, 7500 AE Enschede, The Netherlands \\ ${ }^{2}$ Molecular Nanofabrication Group, MESA+ Institute for Nanotechnology, University of Twente, \\ P.O. Box 217, 7500 AE Enschede, The Netherlands \\ Correspondence to: W. M. de Vos (E-mail: w.m.devos@utwente.nl)
}

Received 24 April 2015; accepted 17 July 2015; published online 6 August 2015

DOI: $10.1002 /$ polb.23795

ABSTRACT: Composite ultrafiltration membranes were fabricated by coating a thin film of self-assembling polystyreneblock-poly(ethylene oxide) (PS-b-PEO) block copolymers and poly(acrylic acid) homopolymers on top of a support membrane. Block copolymers self-assembled into a nanostructure where the minority component forms cylinders, whereas homopolymers reside in the core of the cylinders. Selective removal of the homopolymers led to the formation of pores. The morphology of the polymer layer was controlled by varying the content of homopolymers or polymer concentration of the coating solution, which led to membranes with different molecular weight cutoffs (MWCOs) and permeabilities.
Uniform pores were obtained using low homopolymer contents, whereas high homopolymer contents caused macrophase separation and resulted in large polydisperse pores or craters at the surface. The thickness of the block copolymer film also influenced the structure and performance of the membranes, where a thicker film results in a strong decrease in permeability but a lower MWCO. (c) 2015 Wiley Periodicals, Inc. J. Polym. Sci., Part B: Polym. Phys. 2015, 53, 1546-1558

KEYWORDS: block copolymers; homopolymer; membranes; selfassembly; tuning pore sizes
INTRODUCTION Scarcity of clean water is a worldwide problem, which demands for improvement of current techniques to produce clean water, for example, water filtration by membranes. ${ }^{1}$ Current ultrafiltration membranes are characterized by a wide pore size distribution and/or a low porosity, which leads to either a quite permeable but not very selective membrane or a selective but not very permeable membrane. ${ }^{2}$ Block copolymers that self-assemble into a nanostructure of hexagonally and vertically aligned cylinders have the potential to overcome these limitations. Nanoporous membranes derived from self-assembling block copolymers have a narrow pore size distribution and a high porosity, which would improve both selectivity and permeability. ${ }^{3}$

A block copolymer is a macromolecule that consists of segments (blocks) of two or more repeating units. Some block copolymers have the ability to self-assemble into different nanostructures, depending on the composition and molecular weight of the block copolymer. ${ }^{4,5}$ A morphology of hexagonally packed cylinders perpendicular to the surface is interesting for use in membranes applications, for example, ultrafiltration $^{6,7}$ or drug delivery, ${ }^{8}$ as removal of the cylindrical part results in a membrane with well-ordered and mono- disperse pores. Hence, a very selective and permeable membrane could be produced based on this system.

Fabrication of selective block copolymer-based membranes can be divided into three categories. In the first method, an asymmetric porous membrane is directly formed by rapid solidification of a polymer during fast exchange between a solvent and a nonsolvent, ${ }^{9}$ a technique called "phase inversion." ${ }^{10}$ Although with this approach pore sizes can be tuned by varying the block copolymer molecular weight ${ }^{11}$ or gold deposition inside the pores to decrease the pore diameter, ${ }^{12}$ it has as major drawback that it requires a large amount of (expensive) block copolymers as the whole membrane (including support) is made of the block copolymer.

A second strategy is to fabricate a composite membrane consisting of a thin, selective block copolymer film on top of a membrane support. This block copolymer film can be coated directly on the support membrane by spin or dip coating ${ }^{13,14}$ or transferred to the support membrane in a second step. $^{6-8,15-17}$ Initially, the block copolymer film is a dense film where the blocks form an equilibrium-based selfassembled nanostructure. Subsequent removal of the minority 
(a)
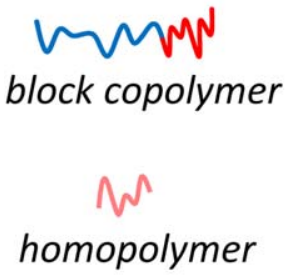
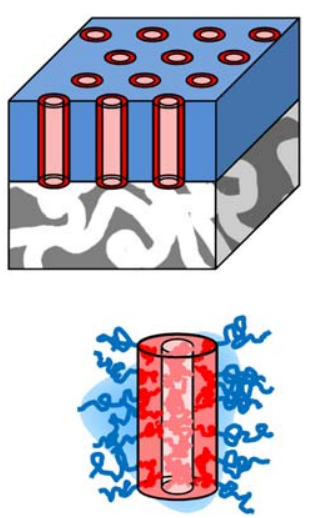

(b)

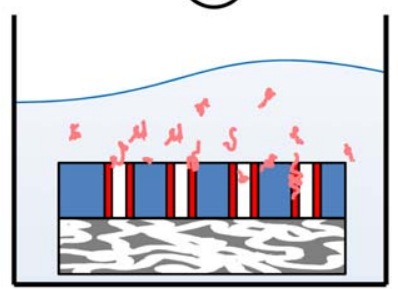

(c)

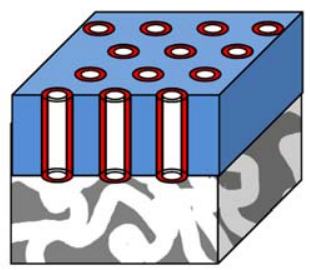

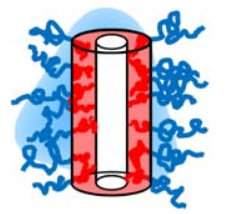

FIGURE 1 Schematic overview of the fabrication of nanoporous composite membranes. (a) A PS- $b$-PEO block copolymer/PAA homopolymer film is coated on top of a support membrane by spin coating. The block copolymer self-assembles into a hexagonally packed cylindrical structure perpendicular to the surface, where the homopolymer resides in the cylinders. Subsequent removal of the homopolymer with a solvent rinse (b) leads to a nanoporous selective top film (c). [Color figure can be viewed in the online issue, which is available at wileyonlinelibrary.com.]

component that forms the cylinders, for example, by etching or UV radiation, results in a porous structure. ${ }^{18-20}$ Although wellordered and monodisperse films can be produced with this technique, the pore size is determined by the size of the minority component of the block copolymer and cannot easily be tuned independently. $^{21}$

A third strategy to create pores is to add a homopolymer to the system and to selectively remove it after a thin film or membrane is casted. Because of favorable interactions of the homopolymer with the block copolymer minority component, the homopolymer resides in the core of the block copolymer cylinders ${ }^{22,23}$ and is subsequently rinsed away to create well-ordered pores. ${ }^{24}$ By varying the content of homopolymers, the pore size and the porosity can be tuned, ${ }^{25-27}$ which leads to membranes with different performances. ${ }^{13}$ Although addition of a small homopolymer fraction can enhance the ordering of the cylindrical block copolymer nanodomains, ${ }^{23}$ larger homopolymer fractions tend to lead to a wider pore size distribution. ${ }^{25,26}$ Finally, this approach provides interesting opportunities for membrane modification, as the minority chain remains inside the pore.

A major challenge for the fabrication of block copolymerbased membranes in the latter two approaches is to control the orientation of the cylinders. This orientation can be either parallel or perpendicular to the surface, but only the latter is suitable for fabricating membranes. However, to minimize the interfacial and surface energy, thermodynamically one of the blocks tends to "wet" the substrate-surface and the solution-air interface because of its more favorable interactions with the surrounding media. This leads to formation of the cylindrical nanodomains that are oriented parallel to the surface. ${ }^{28,29}$ The orientation of the nanodomains can be changed to vertical adding salt that forms complexes with the block copolymer minority chain ${ }^{30,31}$ by modifying the surface to change its interaction with the different copolymer blocks ${ }^{32-35}$ or by inducing a gradient field over the thickness of the film that directs the orientation of the nanodomains. ${ }^{36-40}$ For thin films $(<60 \mathrm{~nm})$ also their thickness influences the orientation. ${ }^{41}$ For films that are casted, a simple method to enhance perpendicular orientation is by fast solidification that causes vertical alignment of the cylindrical nanodomains. ${ }^{42-47}$ However, the vertical orientation only occurs in the upper part of the film. ${ }^{48}$ Because of the challenge of controlling the orientation of block copolymer cylinders, the gyroid morphology has also been used to fabricate nanoporous membranes. ${ }^{49}$ The gyroid morphology has a continuous structure that does not require orientation in order to have interconnected pores; however, it has as a drawback that the tortuosity is higher, thereby decreasing the maximum obtainable permeability.

This article presents a method to produce well-ordered and more monodisperse composite ultrafiltration membranes with tunable pore sizes, and thus filtration properties, using a block copolymer/homopolymer system. Although this approach has been used to fabricate nanofiltration membranes, ${ }^{13}$ this is the first time that this method is applied to ultrafiltration membranes. As we will show, the system behaves quite different for the fabrication of ultrafiltration membranes in terms of how the homopolymers distribute. A composite membrane is fabricated by spin coating a block copolymer/homopolymer film directly on top of a support membrane and subsequently removing the homopolymer with a selective solvent. The block copolymer/homopolymer system under investigation is based on an asymmetric polystyrene-block-poly ethylene oxide (PS- $b$-PEO) block copolymer and a poly(acrylic acid) (PAA) homopolymer. In our work, the block copolymers self-assemble into a hexagonal 


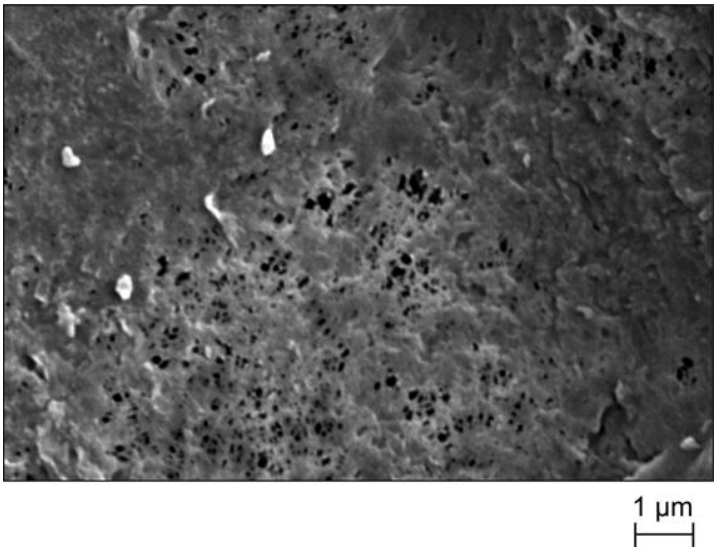

FIGURE 2 SEM surface image $(\times 10,000)$ of the Nadir UV-150 support membrane.

cylindrical structure, where the PEO blocks form the cylindrical nanodomains. PAA coassembles into the core of the cylinders [Fig. 1(a)] because of favorable hydrogen bonding interactions between acrylic acid and ethylene glycol. ${ }^{50}$ Subsequent removal of PAA by a selective solvent [Fig. 1(b)] leads to the formation of nanopores [Fig. 1(c)]. The pore sizes were tuned by varying the content of homopolymer, and the thickness of the block copolymer film was varied by changing the polymer concentration of the coating solution. The composite membranes were challenged to filtration experiments using aqueous poly(ethylene glycol) (PEG) solutions. We show that by simply varying the content of homopolymers, membranes with different pore sizes and different filtration performances [molecular weight cutoff (MWCO)] can be made using just one type and size of block copolymer. The thickness of the block copolymer film was varied, which influences both the permeability and the MWCO. The influence of the composition of the filtration feed solution on the PEG rejection was also studied. Finally, a careful comparison is made of the advantages and disadvantages of this approach when compared with the other approaches to produce block copolymer membranes.

\section{EXPERIMENTAL}

\section{Materials}

Polystyrene- $b$-poly(ethylene oxide) (PS- $b$-PEO) block copolymers P4377-SEO $\left(M_{\mathrm{w}}=62-b-16 \mathrm{~kg} \mathrm{~mol}^{-1}, \mathrm{PDI}=1.08\right)$ and PAA homopolymer P11381-AA $\left(M_{\mathrm{w}}=5.8 \mathrm{~kg} \mathrm{~mol}^{-1}\right.$, PDI = 1.13) were purchased from Polymer Source, Canada. All polymers were used without further purification. Tetrahydrofuran (THF, analytical grade) was purchased from Sigma Aldrich and was used as solvent.

PEG with mean molecular weights of 200, 2000, 6000, $10,000,20,000,35,000$, and $100,000 \mathrm{~g} \mathrm{~mol}^{-1}$ were purchased from Merck (Germany) and were used for filtration experiments. Although PEG and PEO are chemically identical (PEG is normally used for low $M_{\mathrm{w}}$ chains), for clarity, the name PEG is used for filtration solutes and PEO for the block copolymer segment.
Ether glycol (EG), sodium nitrate $\left(\mathrm{NaNO}_{3}\right)$, and sodium azide $\left(\mathrm{NaN}_{3}\right.$; all of analytical grade) were purchased from Merck and were used for gel permeation chromatography (GPC) analysis.

Milli-Q pure water (deionized water purified by a Synergy water purification system of Millipore) was used to make PEG solutions and to dissolve and rinse PAA.

Nadir UV-150 ultrafiltration membranes were kindly provided by Nadir and were used as support membranes. These membranes have pore sizes varying from $50 \mathrm{~nm}$ up to $>300 \mathrm{~nm}$ and a surface porosity of $7.6 \% \pm 1.8 \%$ (Fig. 2).

\section{Preparation of Composite Membranes}

PS- $b$-PEO block copolymers and PAA homopolymers were dissolved in THF and stirred for several hours at room temperature. The total polymer concentration (block copolymer+ homopolymer) was kept constant at 1.0, 1.5, 2.0, or $4.8 \mathrm{wt}$ $\%$, of which the homopolymer weight fraction was varied between 0.05 and 0.40 . THF was chosen as a solvent because it dissolves both PS- $b$-PEO and PAA, and in preliminary experiments, it was found to be a good solvent for preparing defect-free films. Interaction parameters of THF and the block copolymer and homopolymer components are $\chi_{\text {THF-PS }}=0.32, \chi_{\text {THF-PEO }}=0.27$, and $\chi_{\text {THF-PAA }}=0.42,{ }^{51}$ which indicates a good solvent quality of THF toward all polymers.

Composite membranes were prepared by spin coating a polymer solution on a support membrane $(3 \mathrm{~cm} \times 3 \mathrm{~cm})$. The coverage of solution on the support prior to spin coating was $\sim 0.1 \mathrm{~mL} \mathrm{~cm}{ }^{-2}$. Spin coating was performed at $1500 \mathrm{rpm}$ for $2 \mathrm{~min}$ in nitrogen environment at room temperature. To obtain nanopores, the composite membranes were immersed in Milli-Q pure water for $12 \mathrm{~h}$ to dissolve and rinse away the homopolymers. Water was chosen because it dissolves PAA but not PS, which makes it possible to selectively remove the homopolymers without significantly modifying the block copolymer film. The same procedure was used to fabricate films on a silicon wafer to determine the thickness of the block copolymer films and for atomic force microscopy (AFM) and high-resolution scanning electron microscopy (HR-SEM) analyses.

To differentiate the polymer solutions with different homopolymer contents, the following notation is used throughout the article:

$$
f_{\mathrm{PAA}}=\frac{m_{\mathrm{PAA}}}{m_{\mathrm{PAA}}+m_{\mathrm{PS}-b-\mathrm{PEO}}},
$$

where $m_{x}$ is the mass of component $x$ used to make the solution.

Different types of nanoporous block copolymer films were fabricated by using different polymer solutions. An overview of the compositions of all used polymer solutions is presented in Table 1. 
TABLE 1 Overview of Compositions of Polymer Solutions Used to Fabricate Composite Membranes

\begin{tabular}{lll}
\hline Solution & $\begin{array}{l}\text { Polymer Concentration } \\
\text { (wt \%) }\end{array}$ & \\
1 & 1.0 & $f_{\text {PAA }}$ \\
2 & 1.5 & 0.05 \\
3 & 1.0 & 0.05 \\
4 & 1.5 & 0.15 \\
5 & 2.0 & 0.15 \\
6 & 4.8 & 0.15 \\
7 & 1.5 & 0.15 \\
8 & 1.5 & 0.30 \\
\hline
\end{tabular}

All solutions consisted of PS- $b$-PEO, PAA, and THF.

${ }^{a}$ Total polymer concentration (PS- $b$-PEO + PAA).

\section{Characterization}

The block copolymer films were imaged by AFM (Nanoscope 3 , Veeco) in tapping-mode under ambient conditions using silicon cantilevers (Nanosensors) with resonance frequencies between 204 and $497 \mathrm{kHz}$ and spring constants between 10 and $130 \mathrm{Nm}^{-1}$. SEM (Jeol JSM $6010 \mathrm{LA}$, at $5 \mathrm{kV}$ for magnifications up to $\times 10,000$, and HR-SEM, Zeiss Merlin, at $0.5 \mathrm{kV}$ for higher magnifications) was used to visualize and characterize the membranes. Low-magnification SEM samples were dried under vacuum at $30{ }^{\circ} \mathrm{C}$ for $24 \mathrm{~h}$ and then coated with a thin layer of gold using a Balzer Union SCD 040 sputter device. Ellipsometry (Spectroscopic Ellipsometer M-2000V, J.A. Woolam) was used to determine the thickness of the films that were spin coated on silicon wafers.

The average pore diameter and surface porosity were determined from three or four AFM (block copolymer films) or SEM (support membrane) images from a minimum of two samples. The error in pore diameter was calculated using standard rules for error propagation.

\section{Permeation Experiments}

The permeability of the membranes was determined by measuring the flux of Milli-Q pure water at different pressures (0.5-2.5 bar) using a dead-end filtration setup. A membrane (circular, $2.5 \mathrm{~cm}$ in diameter) was placed in a filter holder cell with a volume of $400 \mathrm{~mL}$. The cell was connected to a vessel filled with Milli-Q pure water that was pressurized by compressed nitrogen.
The permeability $\left(\mathrm{L} \mathrm{m}^{-2} \mathrm{~h}^{-1} \mathrm{bar}^{-1}\right.$ ) was calculated as the ratio of the flux over the applied pressure as follows:

$$
\text { Permeability }=\frac{V}{A \cdot t \cdot \Delta P}=\frac{J}{\Delta P},
$$

where $V$ is the permeate volume (L), $A$ is the membrane area $\left(\mathrm{m}^{2}\right), t$ is the time $(\mathrm{h}), J$ is the permeate flux $\left(\mathrm{L} \mathrm{m}^{-2}\right.$ $\mathrm{h}^{-1}$ ), and $P$ is the pressure (bar).

All measurements were performed using at least two different membranes to ensure reproducibility.

\section{PEG Filtration}

The membranes were challenged to PEG filtrations performed at $1.50 \pm 0.04$ bar using the dead-end filtration setup described before. Aqueous solutions were made containing a mixture of PEG components with mean molar masses of 200, 2000, 6000, 10,000, 20,000, 35,000, and 100,000 $\mathrm{g} \mathrm{mol}^{-1}$ in Milli-Q pure water. Each PEG fraction had a concentration of $\sim 0.04 \mathrm{~g} \mathrm{~L}^{-1}$, with a total PEG concentration of $\sim 0.28 \mathrm{~g} \mathrm{~L}^{-1}$. Besides using a PEG mixture, single $M_{\mathrm{w}}$ PEG filtration was also performed using PEG with a mean molar mass of only 10,000 or $100,000 \mathrm{~g} \mathrm{~mol}^{-1}$ with a concentration of $\sim 0.04 \mathrm{~g}$ $\mathrm{L}^{-1}$. An overview of the used PEG molecules and some relevant properties are given in Table 2 .

The composition of the feed, permeate, and retentate was analyzed by GPC. The GPC setup consisted of two SUPREMA $100 \AA$ columns from PSS Polymer Standards Service GmbH (Germany), a HPLC pump from Waters (Millipore B.V., The Netherlands), and a Shodex RI-Detector from Showa Denko $\mathrm{GmbH}$ (Germany). The columns were calibrated using 16 different PEG standards $\left(M_{\mathrm{w}}=62-42,000 \mathrm{~g} \mathrm{~mol}^{-1}\right.$; PSS Polymer Standards Service GmbH, Germany).

Prior to GPC analysis, $\mathrm{NaNO}_{3}$ was added to the samples to achieve a GPC eluent concentration of $0.05 \mathrm{M}$. $\mathrm{NaN}_{3}$ was added $\left(0.05 \mathrm{~g} \mathrm{~L}^{-1}\right)$ to prevent bacteria growth, and EG was added ( $\left.4 \mu \mathrm{L} \mathrm{mL}^{-1}\right)$ as a flow marker (internal standard).

For each GPC analysis, $100 \mu \mathrm{L}$ of a sample was injected into the GPC, which ran at $1 \mathrm{~mL} \mathrm{~min}{ }^{-1}$. Every GPC measurement was performed at least two times to ensure reproducibility.

The rejection $R$ was determined by the following equation:

$$
R=\frac{C_{\text {cell }}-C_{\text {permeate }}}{C_{\text {cell }}},
$$

TABLE 2 Mean Molecular Weight $\left(M_{w}\right)$, Diffusion Constant $\left(D_{\infty}\right)$, and Hydraulic Diameter $\left(d_{\mathrm{h}}\right)$ of the PEG Molecules Used in Filtration Experiments

\begin{tabular}{llllllll}
\hline & $\mathrm{PEG}_{200}$ & $\mathrm{PEG}_{2 \mathrm{k}}$ & $\mathrm{PEG}_{6 \mathrm{k}}$ & $\mathrm{PEG}_{10 \mathrm{k}}$ & $\mathrm{PEG}_{20 \mathrm{k}}$ & $\mathrm{PEG}_{35 \mathrm{k}}$ & $\mathrm{PEG}_{100 \mathrm{k}}$ \\
$M_{\mathrm{w}}\left(\mathrm{g} \mathrm{mol}^{-1}\right)$ & 200 & 2,000 & 6,000 & 10,000 & 20,000 & 35,000 & 100,000 \\
$D_{\infty}{ }^{\mathrm{a}}\left(\mathrm{m}^{2} \mathrm{~s}^{-1}\right)$ & $8.4 \times 10^{-10}$ & $2.1 \times 10^{-10}$ & $1.1 \times 10^{-10}$ & $8.1 \times 10^{-11}$ & $5.4 \times 10^{-11}$ & $3.9 \times 10^{-11}$ & $2.1 \times 10^{-11}$ \\
$d_{\mathrm{h}}{ }^{\mathrm{b}}(\mathrm{nm})$ & 0.6 & 2.3 & 4.4 & 6.0 & 9.1 & 12.7 & 23.8
\end{tabular}

a Diffusion constant of PEG in water was determined at $25^{\circ} \mathrm{C} .{ }^{52}$

${ }^{b}$ Hydraulic diameter was determined using Einstein-Stokes equation. ${ }^{53}$ 


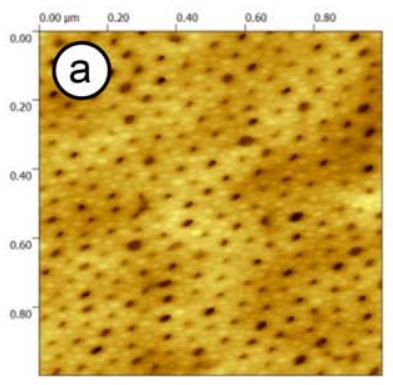

$f_{\text {PAA }}=0.05$

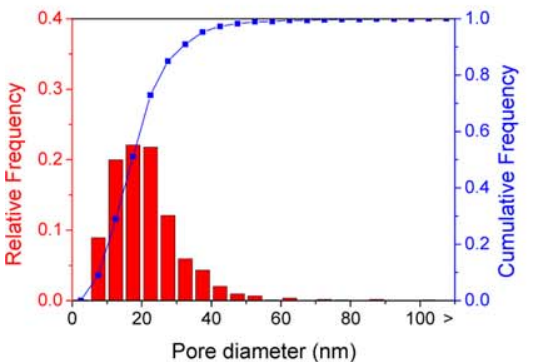

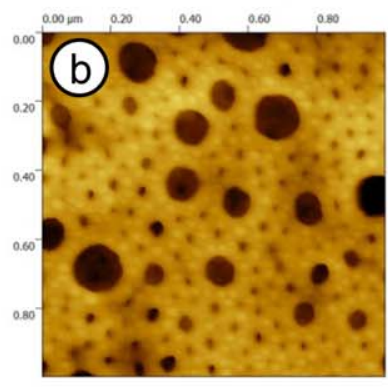

$f_{\text {PAA }}=0.15$

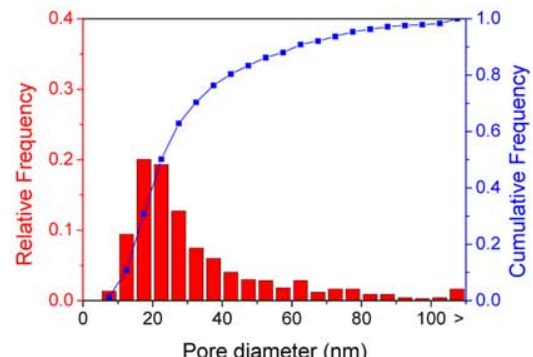

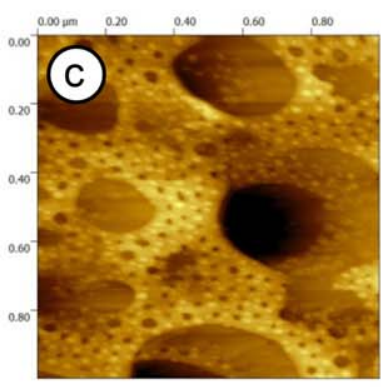

$f_{\text {PAA }}=0.30$

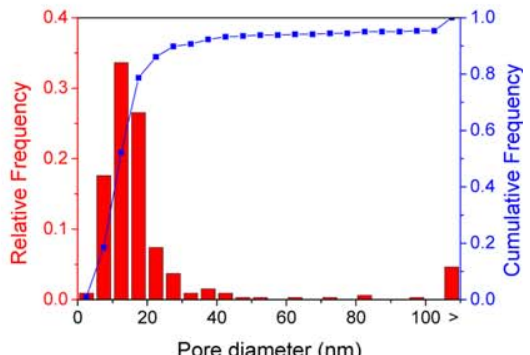

FIGURE 3 AFM height images and relative and cumulative frequencies of pore diameters of films made of PS- $b$-PEO/PAA blends using $f_{\mathrm{PAA}}$ values of (a) 0.05 , (b) 0.15 , and (c) 0.30 . [Color figure can be viewed in the online issue, which is available at wileyonlinelibrary.com.]

where $C_{\text {permeate }}$ is the permeate concentration and $C_{\text {cell }}$ is the concentration inside the test cell. As the setup ran in deadend mode, accumulation of the retained PEG molecules caused the concentration in the membrane cell to rise in time. As it was not possible to monitor the concentration inside the cell in time, the average of the original feed concentration and the final retentate concentration was used as $C_{\text {cell. }}$.

\section{RESULTS AND DISCUSSION}

This section is divided into four parts. First, the effects of the homopolymer content on the pore size, pore size distribution, and porosity of the block copolymer films are investigated. In the second part, the permeabilities of the composite membranes are determined, where both the homopolymer content and the polymer concentration of the solution are varied to understand their effects. In the third part, aqueous PEG solutions with a wide range of PEG molecular weights are filtered using the composite membranes to determine the separation properties of the membranes. From these experiments, it will become clear that changing the homopolymer content and the polymer concentration leads to different composite membranes with different permeability and separation properties. In the final part, the advantages and disadvantages of this method to fabricate composite membranes based on self-assembling block copolymers are discussed.

\section{Tuning the Pore Size}

Figure 3 shows AFM height images of PS- $b$-PEO films made from 1.5 wt \% polymer/THF solutions with different weight fractions of PAA homopolymer $(0.05,0.15$, and 0.30$)$ and their corresponding relative and cumulative pore size frequencies. The dark dots and regions seen on the images correspond to lower altitudes, that is, these dots and regions are pores and craters. In addition, in preliminary experiments, films were fabricated without PAA homopolymer; however, in these films, no pores were detected. In the images, two types of pores can be distinguished. First, small pores in the range of 5-40 $\mathrm{nm}$, which seem to be ordered and uniform, and second, larger randomly distributed pores up to several hundreds of nanometers. The small pores are formed by "microphase separation," where homopolymers reside in the center of the packed block copolymer cylinders. However, the larger pores are formed by "macrophase separation," where the homopolymers form their own separated regions outside the block copolymer nanodomains. These phenomena of microphase and macrophase separation have been well described by Jeong et al. ${ }^{22}$ The comparison of Figure $3(\mathrm{a}-\mathrm{c})$ shows that the small pores formed by microphase separation become slightly larger when $f_{\text {PAA }}$ is increased from 0.05 to 0.15 , where average pore sizes are obtained of $21 \mathrm{~nm}$ and $26 \mathrm{~nm}$, respectively, taking only pores in the range of $0-100 \mathrm{~nm}$ into account. When the PAA fraction is further increased to 0.30 , the size of the smaller pores decreases to $16 \mathrm{~nm}$. This is surprising, because if all homopolymers reside in the block copolymer cylinders, the average pore size should increase with increasing homopolymer content. $^{25,26}$ The reason for this population of the pores to become smaller is the relative depletion of the amount of homopolymer available for their formation by microphase separation due to the parallel formation of the larger domains by macrophase separation. For $f_{\mathrm{PAA}}=0.05$, all pores seem ordered and uniform, but for $f_{\mathrm{PAA}}=0.15$, some random 

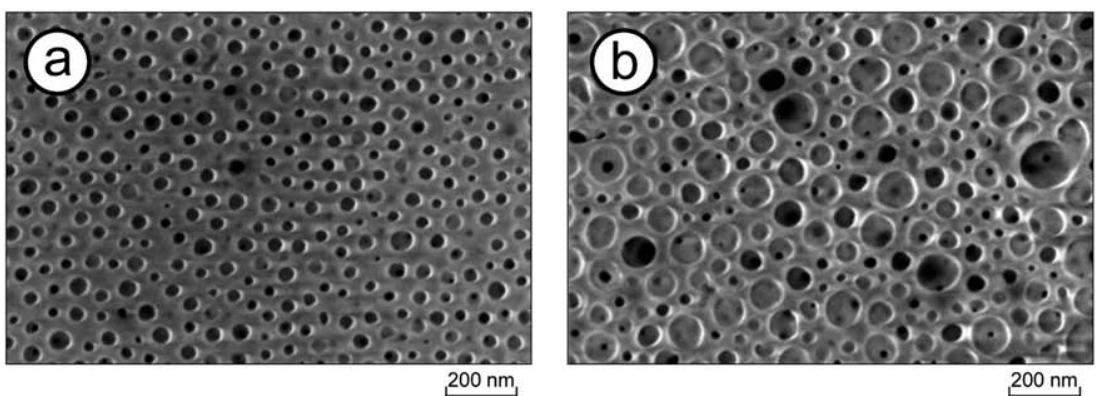

$200 \mathrm{~nm}$
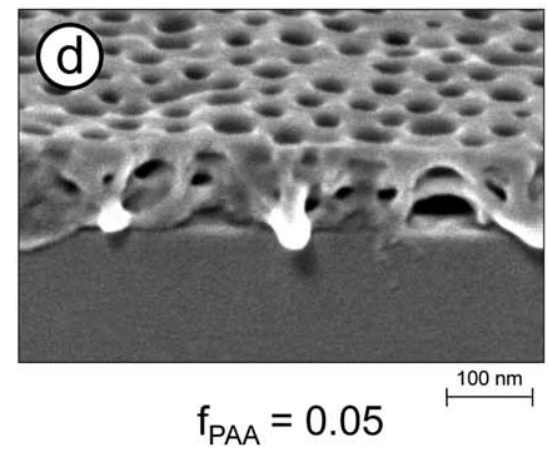

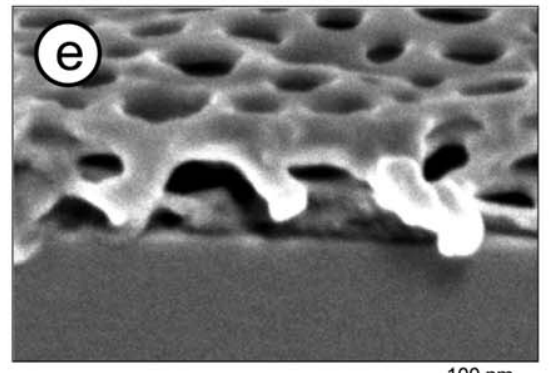

$f_{P A A}=0.15$
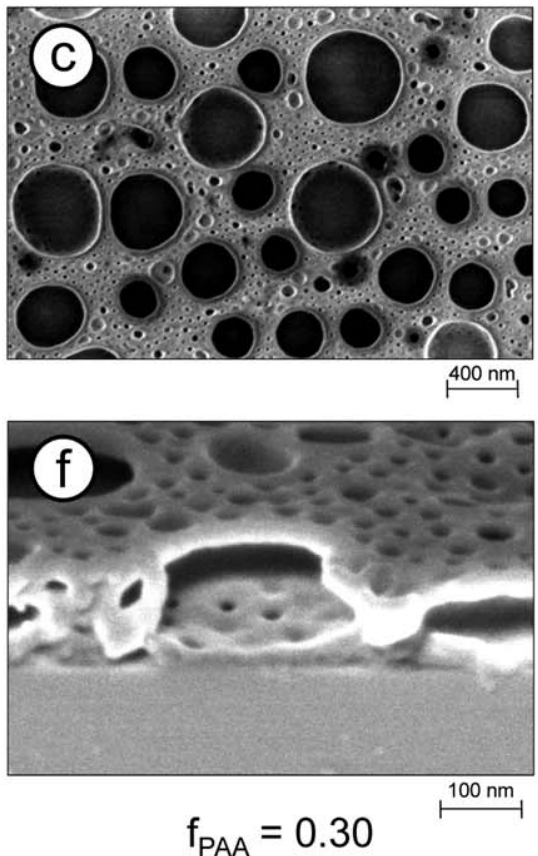

FIGURE 4 HR-SEM surface (upper row) and cross-section (lower row) images of films made of PS- $b$-PEO/PAA blends using $f_{\mathrm{PAA}}$ values of ( $a$ and d) 0.05, (b and e) 0.15, and (c and f) 0.30. Magnifications are $\times 200,000$ (a-c), 314,000 (d), 350,000 (e), and 310,000 (f).

larger pores start to appear because of a small degree of macrophase separation. When an even higher $f_{\mathrm{PAA}}$ of 0.30 is used, very large dark areas can be seen with diameters up to several hundreds of nanometers, which are either big pores or craters. As more homopolymers form larger regions outside the block copolymers, less homopolymers reside inside the block copolymer cylinders. This causes the smaller pores (formed by microphase separation) to decrease in size.

Figure 4 shows HR-SEM surface and cross-section images of the same films discussed before. The surface images confirm the pore sizes and pore size distribution determined by AFM. Interestingly, the larger pores $(>100 \mathrm{~nm})$ in Figure $4(\mathrm{~b})$ seem to be craters that have smaller pores at the bottom. The entire morphology of the films becomes clear in the crosssection images. For $f_{\mathrm{PAA}}=0.05$ Figure $4(\mathrm{a})$ and 0.15 Figure 4(b), the cross-section SEM images show that most pores penetrate the entire thickness of the film, which is $\sim 90 \mathrm{~nm}$. However, not all pores seem to penetrate the entire thickness of the film as a single channel, but instead they seem interconnected with other channels to form a network of interconnected pores beneath the surface. Apparently, the orientation of the block copolymer domains changes already directly underneath the surface, leading to this type of morphology.

For $f_{\mathrm{PAA}}=0.30$, the big pores also seem to be craters that do not span the entire thickness of the film. The bottom of the craters consists of a dense layer that contains the small microphase separation pores that are also seen on the surface of the film.

At relatively high homopolymer contents $\left(f_{\mathrm{PAA}}=0.40\right)$, microphase separation no longer occurs and small pores are not formed (Fig. 5). Instead, a dense structure is obtained with large craters of 1-3 $\mu \mathrm{m}$ in diameter, which seem to appear at the surface and not completely span the entire thickness of the block copolymer film.

The effect of the increasing homopolymer content on the morphology of the films formed differs from the previous reports on the PS- $b$-PEO/PAA mixtures, ${ }^{13,50}$ where instead of the macrophase separation, a transition to lamellar morphology was observed at larger homopolymer contents. The difference between both studies is that the PS- $b$-PEO in our system has a relatively high $M_{\mathrm{w}}$, which is required for obtaining larger pores in the ultrafiltration range. In block copolymer/homopolymer systems, macrophase separation starts occurring at lower homopolymer contents when a higher

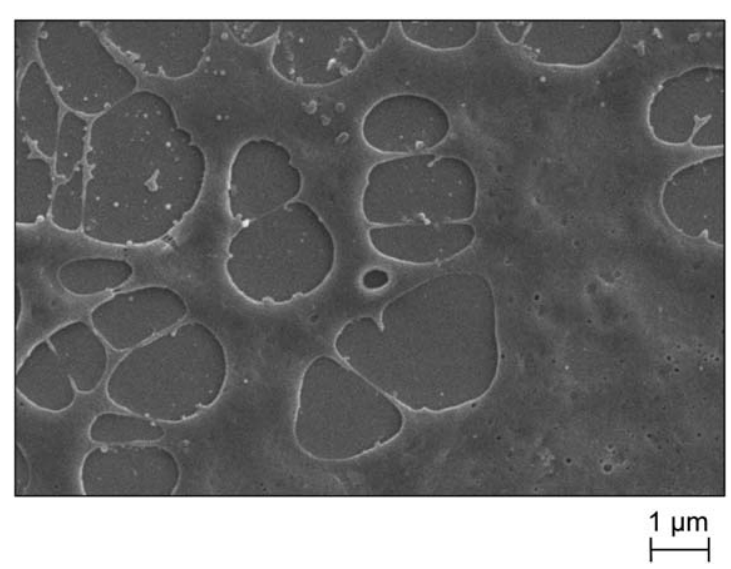

FIGURE 5 SEM surface image $(\times 10,000)$ of a film made of a PS- $b$-PEO/PAA blend with a $f_{\mathrm{PAA}}$ value of 0.40 .

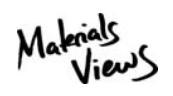

WWW.MATERIALSVIEWS.COM 


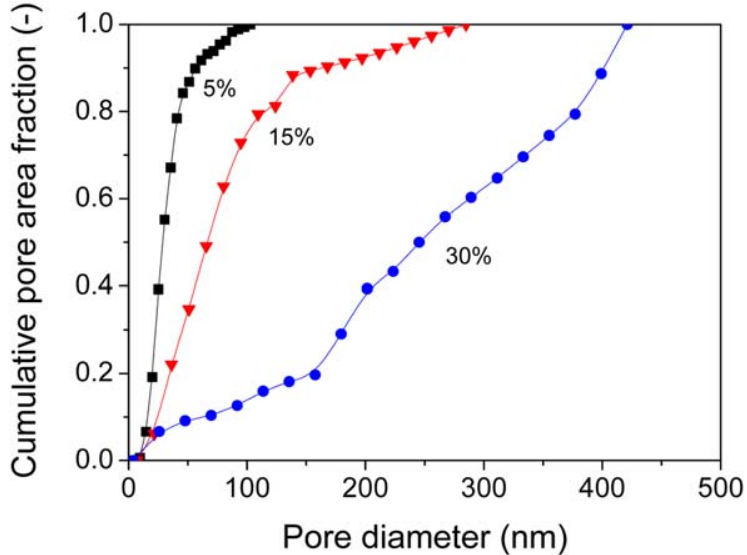

FIGURE 6 Cumulative pore area fraction for increasing pore diameter of block copolymer top films made with $1.5 \mathrm{wt} \%$ polymer solutions with $f_{\mathrm{PAA}}=0.05,0.15$, and 0.30 . [Color figure can be viewed in the online issue, which is available at wileyonlinelibrary.com.]

$M_{\mathrm{w}}$ block copolymer is used. ${ }^{25}$ As already indicated by our results, this effect makes it more challenging to fabricate ultrafiltration membranes using a block copolymer/homopolymer system.

Although the number fraction of small pores is high for all block copolymer films (Fig. 3), the effect of the larger pores on the total pore area is more significant. Figure 6 shows the cumulative pore area fraction for increasing pore diameter of films made with different homopolymer contents. A steep curve is obtained for $f_{\mathrm{PAA}}=0.05$, which indicates that all small pores contribute significantly to the total pore area. For $f_{\mathrm{PAA}}=0.15$, the curve is less steep because the pores become less monodisperse. After $\sim 100 \mathrm{~nm}$, the graph levels off due to the larger pores formed by macrophase separation that contribute to $\sim 20 \%$ of the total pore area. For $f_{\mathrm{PAA}}=0.30$, an undefined graph is obtained where $\sim 80 \%$ of the total pore area is obtained from pores larger than $100 \mathrm{~nm}$.

As larger pores give rise to a higher permeability, ${ }^{10}$ one would expect that the larger pores formed by macrophase separation will determine the properties of the fabricated membrane. However, the AFM and SEM images (Figs. 3 and 4) show that the large pores are not necessarily straightthrough pores. Some large dark spots have a more funnellike shape and show smaller pores at the bottom, indicating that some or all pores are more like craters rather than pores that span the thickness of the film. In that case, the craters could potentially influence the performance of the membrane, rather than determining. In the next paragraph, we will discuss the influence of the film thickness and homopolymer content on the permeability.

\section{Permeability}

\section{Effect of Film Thickness}

Figure 7 shows the pure water permeability of prepared composite membranes as a function of the total polymer concentration (block copolymer + homopolymer) of the coating solution. For the fabrication of all membranes, $f_{\text {PAA }}$ was kept constant at 0.15 . The highest permeability is obtained using a $1.0 \mathrm{wt} \%$ polymer solution, which results in a membrane with a permeability of $19.4 \mathrm{~L} \mathrm{~m}^{-2} \mathrm{~h}^{-1} \mathrm{bar}^{-1}$. When a higher polymer concentration is used, the permeability decreases. Permeabilities of 10.6 and $2.1 \mathrm{~L} \mathrm{~m}^{-2} \mathrm{~h}^{-1}$ bar $^{-1}$ are obtained using a polymer concentration of 1.5 and 2.0 wt $\%$, respectively. The lowest measurable permeability is obtained when a polymer concentration of $4.8 \mathrm{wt} \%$ is used, which leads to a permeability of $0.1 \mathrm{~L} \mathrm{~m}^{-2} \mathrm{~h}^{-1} \mathrm{bar}^{-1}$ only. It was not possible to go beyond $19 \mathrm{~L} \mathrm{~m}^{-2} \mathrm{~h}^{-1}$ bar $^{-1}$ by using a lower polymer concentration, as this caused defects in the top film (as observed by SEM).

The influence of the polymer concentration on the permeability can be explained by the obtained thickness of the block copolymer top films. A thicker film is obtained when the polymer concentration in the solution during spin coating is increased. ${ }^{54}$ It was found that the thickness of thin films spin coated on silica wafers increases linearly from 70 to $430 \mathrm{~nm}$ using polymer concentrations in the range of 1.0-4.5 wt \%, which is a good indication for the block copolymer film thicknesses of our composite membranes. A thicker film increases the hydraulic resistance of the membrane and thereby decreases its permeability. However, our observed decrease in permeability is much larger than expected on the basis of just a change in thickness.

Films made from block copolymers often have perpendicular orientated block copolymers at the top, initiated by fast evaporation, but still have cylinders with a different orientation deeper inside the film. ${ }^{28,29,48}$ Thus, a thicker film fabricated by using a higher polymer concentration will lead to a

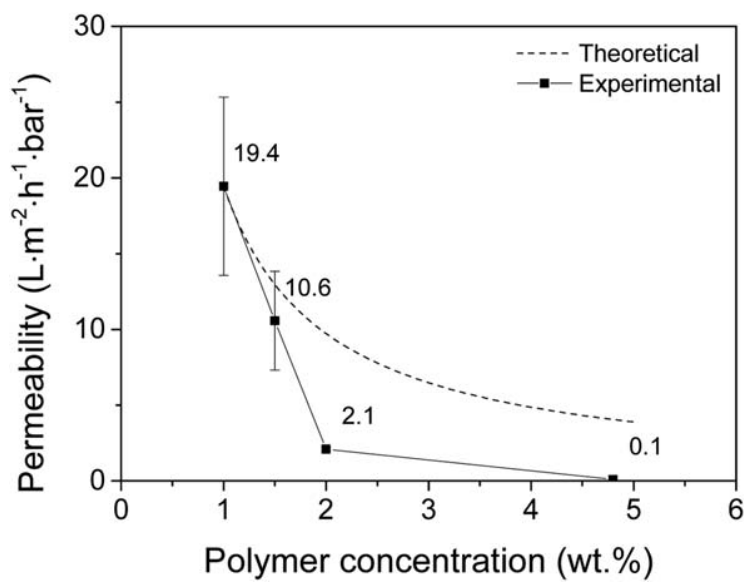

FIGURE 7 Pure water permeability of composite membranes (E) as a function of the total polymer concentration (block copolymer + homopolymer) of the solution used for spin coating. $f_{\mathrm{PAA}}$ was kept constant at 0.15 . Line is plotted to guide the eye. Theoretical values (---) based on the assumption that the flux is inversely proportional to the thickness of the film, with 1.0 wt $\%$ polymer concentration (19.4 $\left.\mathrm{L} \mathrm{m}^{-2} \mathrm{~h}^{-1} \mathrm{bar}^{-1}\right)$ as reference. 


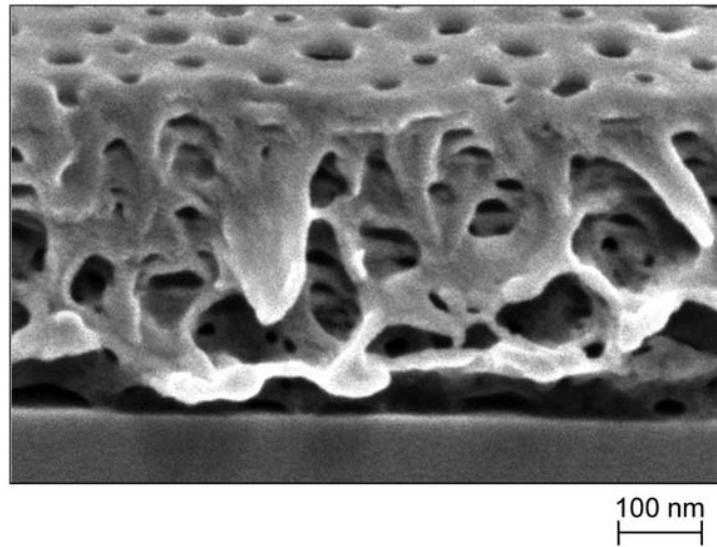

FIGURE 8 HR-SEM cross-section image (magnification, $\times 340,000$ ) of a film made using a $4.8 \mathrm{wt} \%$ PS- $b$-PEO/PAA/THF solution with a $f_{\mathrm{PAA}}$ value of 0.15 .

thicker film of block copolymers having a different and undesired orientation. When in our case, PAA homopolymers microphase-separate inside these block copolymer domains, not all pores will go straight-through, but will also have different orientations and be less interconnected. Figure 8 shows an HR-SEM cross-section of a 380-nm-thick film made with a 4.8 wt $\%$ polymer solution with a $f_{\text {PAA }}$ value of 0.15 . The orientation of the polymer matrix changes deeper inside the film to a more horizontal orientation. However, most part of the film seems highly permeable and also the horizontal morphology still seems permeable. It seems plausible that a thicker film increases the change of having dead-end pores within this structure, something that would indeed lead to the observed lower permeability.

The theoretical permeability values are also shown in Figure 7, which are based on the assumption that the flux is inversely proportional to the thickness of the film and have the 1.0 wt \% polymer concentration $\left(19.4 \mathrm{~L} \mathrm{~m}^{-2} \mathrm{~h}^{-1} \mathrm{bar}^{-1}\right.$ ) as reference point. The decline of the experimentally obtained permeabilities is much faster than the expected decline, which implies that the resistance of the block copolymer film exponentially increases with the thickness of the block copolymer film.

\section{Effect of Homopolymer Content}

Figure 9 shows the water permeability as a function of the homopolymer content of the solution used to fabricate the top film of the composite membrane. The total polymer concentration for all solutions was kept constant at 1.5 wt \%. In preliminary experiments, no water permeation was detected when a membrane was fabricated without addition of PAA. A permeability of $2.9 \mathrm{~L} \mathrm{~m}^{-2} \mathrm{~h}^{-1} \mathrm{bar}^{-1}$ is obtained for $f_{\text {PAA }}=0.05$. When a higher fraction of 0.15 is used, a higher permeability $\left(10.6 \mathrm{~L} \mathrm{~m}^{-2} \mathrm{~h}^{-1}\right.$ bar $\left.^{-1}\right)$ is also obtained. Surprisingly, using a higher $f_{\text {PAA }}$ value of 0.30 does not increase the permeability, and using an even higher fraction of 0.40 leads to a lower permeability again. Intuitively, one would expect a higher permeability for increasing homopolymer content, as at higher homopolymer content, more voids are created when the homopolymers are rinsed away, leading to a higher permeability. However, Figure 9 shows that there is a maximum permeability for $f_{\mathrm{PAA}}$ in the range of $0.15-0.30$. This is caused by the transition from microphase separation to macrophase separation (Figs. 3-6), which leads to a structure that has more voids but is less permeable. For $f_{\text {PAA }}=0.30$, the reproducibility of the membranes is also less. Probably in some membranes, more large macrophaseseparated areas perforate the entire thickness of the block copolymer film than others, thereby increasing the permeability. This phenomenon also gives rise to a high standard deviation of the permeability (Fig. 9).

The high resistance of the block copolymer film becomes clear when the experimentally obtained permeabilities are compared with theoretical approaches. According to the Hagen-Poiseuille equation for laminar flow through a tube, the lowest possible permeability of our film should be $\sim 1600 \mathrm{~L} \mathrm{~m}^{-2} \mathrm{~h}^{-1} \mathrm{bar}^{-1}$ (diameter pores $=24 \mathrm{~nm}$, porosity $=$ 0.1 , tortuosity $=1$, thickness film $=400 \mathrm{~nm}) .{ }^{10}$ Taking into account the porosity of the support membrane $(7.6 \%)$, the maximum possible permeability is lowered to $115 \mathrm{~L} \mathrm{~m}^{-2}$ $\mathrm{h}^{-1}$ bar $^{-1}$, which is slightly lower than the permeability of the support membrane $\left(\sim 180 \mathrm{~L} \mathrm{~m}^{-2} \mathrm{~h}^{-1} \mathrm{bar}^{-1}\right.$, as determined experimentally). As the experimentally obtained permeabilities are at least an order of magnitude lower, and the thickness of the top film influences the permeability of the composite membrane, it is clear that the block copolymer film determines the hydraulic resistance of the composite membrane.

Besides a low effective porosity (product of the porosities of the support membrane and block copolymer film) and less interconnected pores, some other issues may decrease the permeability as well. First, it is known that during rinsing away of homopolymers by a selective solvent, not all the homopolymers might be removed. ${ }^{55}$ When homopolymers are removed in a relatively thick film $(\geq 70 \mathrm{~nm})$, not all homopolymers situated deeper into the film have the

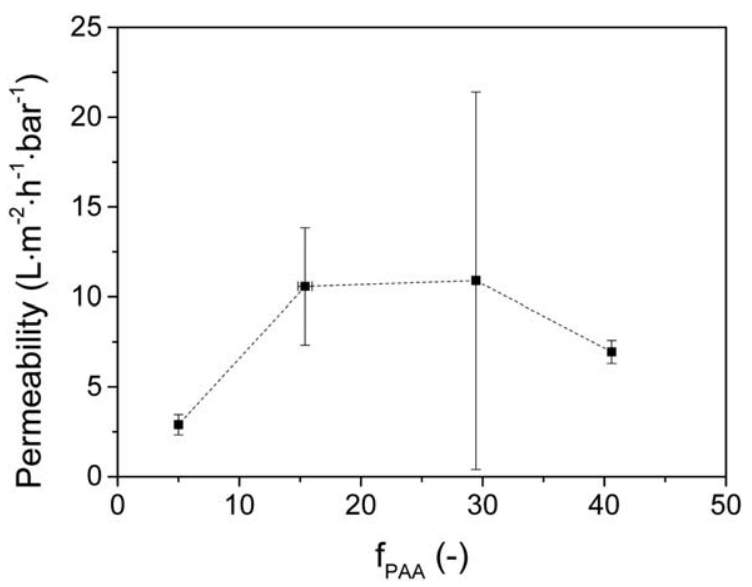

FIGURE 9 Water permeability $\left(\mathrm{L} \mathrm{m}^{-2} \mathrm{~h}^{-1} \mathrm{bar}^{-1}\right)$ as a function of $f_{\mathrm{PAA}}$ using $1.5 \mathrm{wt} \%$ polymer/THF solutions during film formation. 

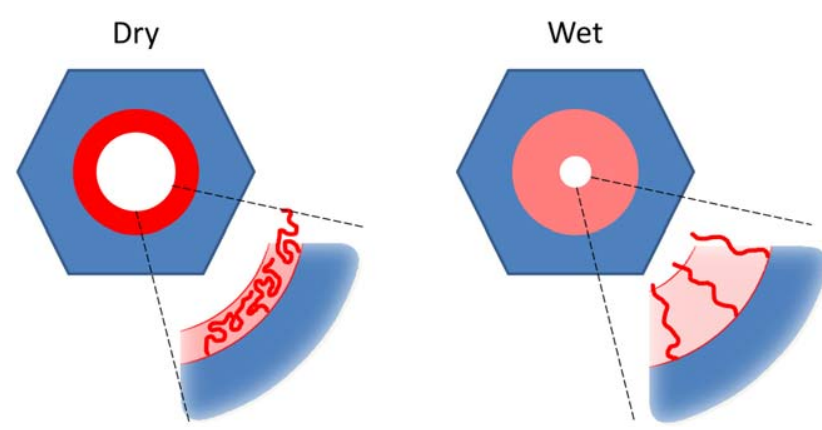

FIGURE 10 Schematic illustration of the state of PS- $b$-PEO domains in dry and wet state. In dry state, the PEO chains (in red) are solidified and form the wall of the pore. In wet state, the PEO chains are swollen, by (or even dissolved in) water, thereby decreasing the hydraulic diameter of the pore. [Color figure can be viewed in the online issue, which is available at wileyonlinelibrary.com.]

possibility to diffuse out of the film, which results in funnellike pores where the pore diameter becomes smaller deeper into the film. It is likely that this phenomenon initially plays a role in our relatively thick top films and is enhanced even more when the orientation of the block copolymers changes. However, as our homopolymer is soluble in water, all accessible homopolymers should be rinsed away when water permeates the pores. Another phenomenon that is expected to lower the permeability is swelling of the PEO chains of the block copolymers that cover the surface of the walls of the pores. Figure 10 shows schematically how the pore size changes from the dry to the wet state. In the dry state, the PEO chains form the walls of the pores, as seen in the AFM and SEM images. However, as PEO is soluble in water, the PEO blocks will swell when the pores are filled with water, thereby increasing the hydraulic resistance of the pores. This means that the permeability of the pores will be lower than what is expected based on the pore size as determined by

\section{a}

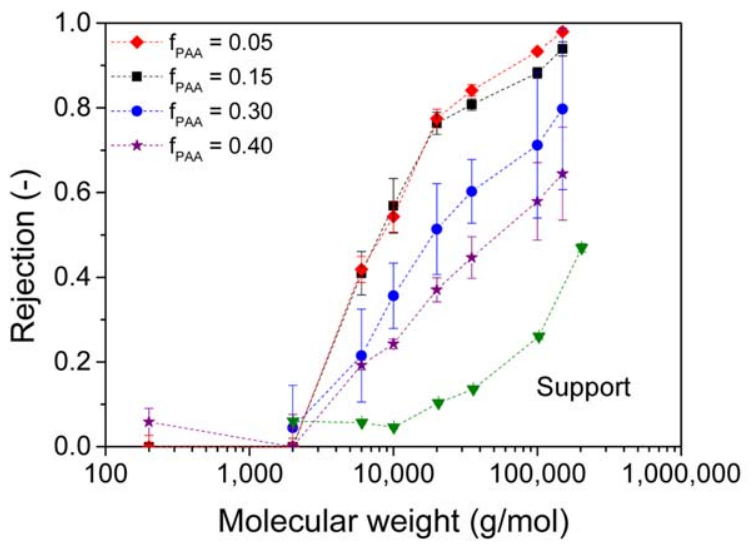

AFM and SEM. Although the PEO layer lowers the permeability, the presence of PEO is certainly not unfavorable. PEO layers are well established to act to prevent fouling, especially by protein molecules. ${ }^{56,57}$ However, this specific effect is beyond the current investigation.

Our experimentally obtained permeabilities (of $19 \mathrm{~L} \mathrm{~m}^{-2}$ $\mathrm{h}^{-1}$ bar $^{-1}$ ) are much higher when compared with the permeabilities of other block copolymer-based composite membranes found in the literature, which varied from $1.2 \mathrm{~L} \mathrm{~m}^{-2}$ $\mathrm{h}^{-1}$ bar $^{-1}$ for a composite block copolymer membrane made by etching away the cylindrical domains ${ }^{48}$ to $1-5 \mathrm{~L} \mathrm{~m}^{-2} \mathrm{~h}^{-1}$ bar $^{-1}$ for a composite block copolymer membrane fabricated by removing homopolymers to create pores. ${ }^{13}$ We showed that the permeability of the block copolymer composite membranes is determined by the polymer concentration of the coating solution. Our use of low polymer concentrations to fabricate composite membranes explains why some composite membranes fabricated in this work have much higher permeabilities than block copolymer-based composite membranes found in the literature.

\section{Filtration}

The composite membranes were challenged to dead-end filtration of an aqueous PEG solution with a variety of molecular masses.

Figure 11(a) shows the rejection of different PEG mean molar masses using composite membranes with a block copolymer top film made from $1.5 \mathrm{wt} \%$ polymer solutions with homopolymer weight fractions of $0.05,0.15,0.30$, and 0.40 . The PEG rejection by the native Nadir UV-150 support membrane is much lower than the PEG rejections of our fabricated composite membranes, which implies that the block copolymer film is the selective layer of the composite membrane. The rejection curve starts after $\sim 2000 \mathrm{~g} \mathrm{~mol}^{-1}$ for all composite membranes, indicating that PEG particles with a

\section{b}

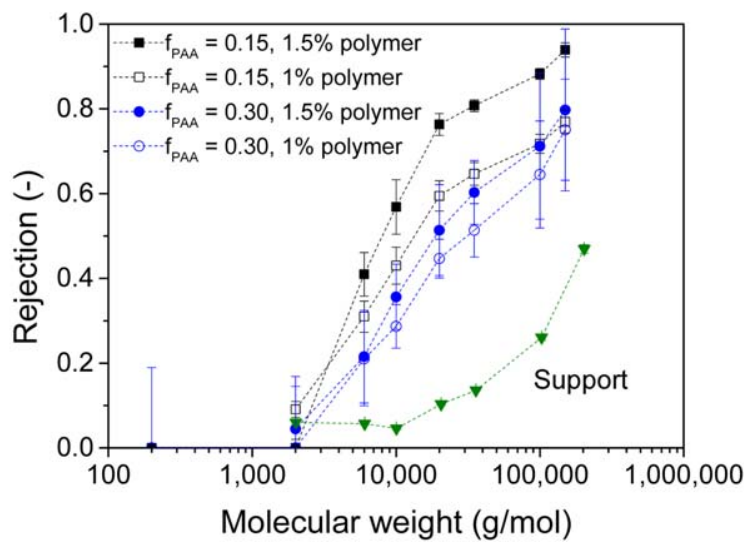

FIGURE 11 Rejection of PEG mean molar masses using different composite membranes. (a) Block copolymer top film made from 1.5 wt \% polymer solutions with homopolymer weight fractions of $0.05,0.15,0.30$, and 0.40 . (b) Block copolymer top film made from 1.0 and $1.5 \mathrm{wt} \%$ polymer solutions with homopolymer weight fractions of 0.15 and 0.30 . Dotted lines are shown to guide the eye. [Color figure can be viewed in the online issue, which is available at wileyonlinelibrary.com.] 
a

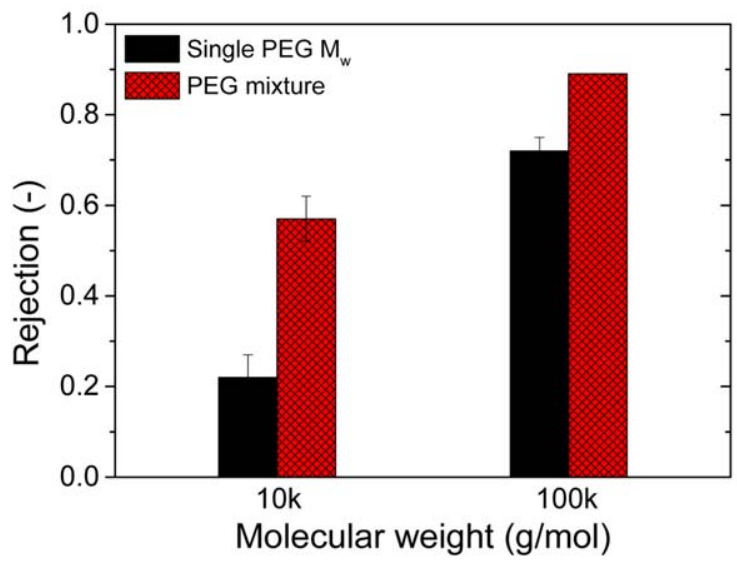

b

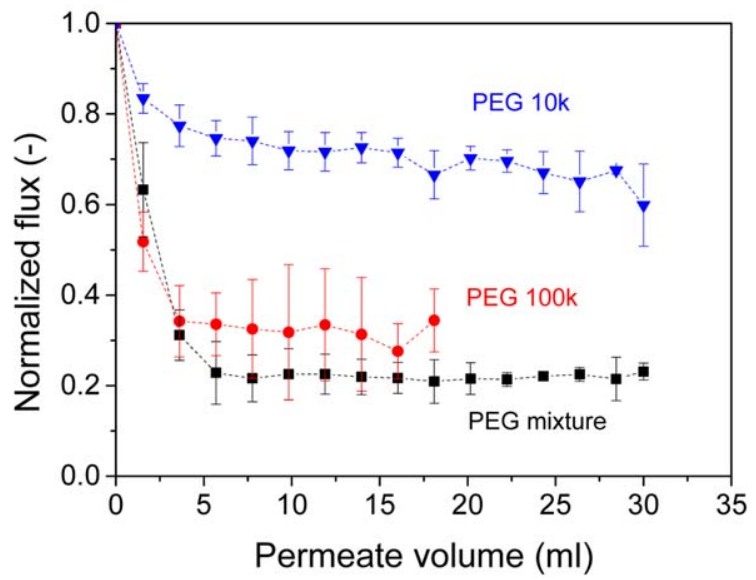

FIGURE 12 (a) Rejection of $\mathrm{PEG}_{10 \mathrm{k}}$ and $\mathrm{PEG}_{100 \mathrm{k}}$ using single $M_{\mathrm{w}} \mathrm{PEG}$ and a mixture of different $M_{\mathrm{w}}$ PEG for filtration. (b) Normalized flux, normalized on the pure water flux. Membrane used made from a $1.5 \mathrm{wt} \%$ polymer solution with $f_{\mathrm{PAA}}=0.15$. [Color figure can be viewed in the online issue, which is available at wileyonlinelibrary.com.]

hydraulic diameter smaller than $2.3 \mathrm{~nm}$ are not rejected. The filtration curves become less steep when a larger amount of homopolymers is used. The smallest pores are obtained for $f_{\mathrm{PAA}}=0.05$, resulting in the highest rejection of PEG molecules. When a higher homopolymer content is used, larger pores are obtained that are accessible for larger PEG molecules, which results in a lower rejection. PEG molecules of $\sim 75,000$ and $\sim 130,000 \mathrm{~g} \mathrm{~mol}^{-1}$ are for $90 \%$ rejected using $f_{\text {PAA }}=0.05$ and 0.15 , respectively. These values correspond to hydraulic diameters of 20 and $28 \mathrm{~nm}$, which are similar to the average size of the microphase separation pores of the membranes (see Fig. 3). The rejection curves of membranes made using $f_{\mathrm{PAA}}=0.30$ and 0.40 are significantly lower than the rejection curves for $f_{\mathrm{PAA}}$ values of 0.05 and 0.15 . This happens because the larger pores formed by macrophase separation that span through the entire block copolymer film thickness do not have any rejection in the range of the molecular weights used in these filtration experiments. Although many macrophase separation regions appear as craters on top of the block copolymer film, there are still regions that span the entire thickness of the film, thereby significantly influencing the selectivity of the membrane. However, this experiment demonstrates clearly that the separation behavior can be tuned by simply varying the amount of homopolymers.

Figure 11(b) shows the effect of the polymer concentration on the filtration performance. The rejection of the different PEG mean molar masses is displayed using composite membranes with a block copolymer top film made from 1.0 and 1.5 wt $\%$ polymer solutions. When $f_{\text {PAA }}$ is kept constant (0.05 or 0.15$)$, a higher total polymer concentration leads to higher rejections. This implies that when the top film is thicker, it influences the separation behavior of the membrane. A different morphology of the block copolymer domains deeper in the film may explain this behavior, ${ }^{48}$ as well as different process conditions such as permeabilities.
The trends found in our experiments are different than the trends that Li et al. ${ }^{13}$ found for their PS- $b$-PEO/PAA-based composite nanofiltration membranes. They found that increasing the homopolymer content always leads to higher permeabilities but not to different separation behaviors. In contrast, we find that changing the homopolymer content leads to different separation behaviors for our ultrafiltration membranes. In addition, a maximum permeability is also obtained when the homopolymer content is varied. The main difference between the two approaches is the used molecular weight of the block copolymer, which determines the maximum homopolymer content before macrophase separation occurs. $^{25}$ The much smaller block copolymer used by $\mathrm{Li}$ et al. did not come to macrophase separation when $f_{\mathrm{PAA}}$ was increased to 0.30 but instead led to a change of domain orientation (from cylindrical to lamellae). In our case, where we use larger block copolymers, increasing the homopolymer weight fraction leads to the formation of macrophaseseparated areas of homopolymers that influence the performance of the composite membrane in a very different way.

\section{Effect of Feed Solution}

The previous section showed how the composition of the coating solutions determines the separation behavior of the formed composite membrane. However, the composition of the feed solution can also influence filtration results, which is often neglected in other studies on composite block copolymer-based membranes. To investigate the effect of the feed solution on the PEG rejection, additional filtration tests were performed using just one $M_{\mathrm{w}}$ of PEG in the feed solution. Single $M_{\mathrm{w}}$ filtrations were performed with low- and high- $M_{\mathrm{w}}$ PEG (10k and $100 \mathrm{k}$ ) using a membrane made from a 1.5 wt $\%$ polymer solution with $f_{\mathrm{PAA}}=0.15$. The concentration of the single $M_{\mathrm{w}}$ PEG used was the same as the concentration of the corresponding PEG in the PEG mixture filtration experiments $\left(0.04 \mathrm{~g} \mathrm{~L}^{-1}\right)$. 
Figure 12(a) shows the rejection of the individual PEG $M_{\mathrm{w}} \mathrm{s}$ for both types of filtration experiments. The rejection of $\mathrm{PEG}_{10 \mathrm{k}}$ is $\sim 0.57$ during the PEG mixture filtration, but is more than halved in the single $M_{\mathrm{w}}$ filtration $(\sim 0.22)$. Moreover, the rejection of the higher $M_{\mathrm{w}}$ PEGs is lower during single $M_{\mathrm{w}}$ filtration, but the decrease is less dramatic.

Figure 12(b) shows the pure water normalized flux as a function of the permeate volume during the different filtration experiments. A fast flux decline is observed during the PEG mixture filtration in the initial stage of the experiment, where the flux rapidly decreases to $\sim 20 \%$ of its initial flux. After that the flux is stagnant, indicating the formation of a cake layer. ${ }^{58}$ A similar trend is observed during the $\mathrm{PEG}_{100 \mathrm{k}}$ single $M_{\mathrm{w}}$ filtration where the flux rapidly drops to $\sim 35 \%$ of its initial value. During the $\mathrm{PEG}_{10 \mathrm{k}}$ single $M_{\mathrm{w}}$ filtration, a flux decline is also observed; however, this is far less. The flux slowly decreases from $\sim 80 \%$ to $\sim 75 \%$ and does not stabilizes in in the first $30 \mathrm{~mL}$ of permeate volume. The graphs indicate that most of the flux decline during the PEG mixture filtration is caused by the larger PEG molecules. The larger PEG molecules have a stronger rejection than the smaller PEG molecules and will be more abundant at the surface of the membrane. Because of their low diffusion constants, larger PEG molecules will enhance concentration polarization even more, which causes an additional resistance. This can also influence the separation behavior of the membrane. ${ }^{59,60}$ To conclude this paragraph, the MWCO is a function of conditions chosen, and thus, absolute rejection values may change depending on specific experiments. However, the observed trends are correct.

\section{Advantages and Disadvantages of the Method}

Coating a thin block copolymer-based film on top of a composite membrane is a promising method to fabricate very selective and highly permeable membranes for liquid filtrations. Membranes with different separation properties can be made using just one type of block copolymer by simply varying the amount of homopolymers. When a selective layer of $\sim 100 \mathrm{~nm}$ is coated on a support membrane, only $\sim 0.1 \mathrm{~g}$ $\mathrm{m}^{-2}$ polymer is needed, and this is a huge advantage in terms of the cost effectiveness and durability. However, this method also has some problems that need to be overcome. First, spin coating is a powerful tool for fabricating composite membranes on laboratory scale; however, it cannot easily be scaled up to industrial sizes. Fortunately, dip coating is a good alternative to spin coating. This can be used to coat membranes with a larger area and with different geometries. If the solvent evaporation rate can be controlled, the solidification process is similar to spin coating. The drawback of this method is that more solution is needed, making spin coating more practical for laboratory-scale experiments than for scale up. A second problem is intrusion of the polymer solution into the pores of the support membrane during coating. This can lead to blockage of the pores and thereby decreasing the permeability or to unsuccessful covering of the support membrane. Filling the pores with a fluid that is either miscible of immiscible with the polymer solvent could potentially solve this problem; however, in initial experiments, we found that this can also create large defects in our block copolymer film. The way to deal with this problem seems to be to find an optimum between the pore size of the support membrane and the polymer concentration of the block copolymer coating solution. Smaller pores of the support membrane cause less intrusion and make it possible to use a lower polymer concentration of the coating solution, but come at the cost of the permeability of the support membrane. This is not a problem when the block copolymer film has the dominating hydraulic resistance; however, when the block copolymer film becomes thinner, the support membrane can contribute the most to the hydraulic resistance. In addition, the pores of the support membrane can become so small that they start to reject particles in the same range of sizes as the block copolymer film, thereby making the latter obsolete. Finally, it can be concluded that the thickness of the block copolymer film should be minimized to obtain a high permeability, and the occurrence of macrophase separation (at higher homopolymer content) limits the range of pore sizes that can be obtained.

\section{CONCLUSIONS}

Coating a thin film made from self-assembling PS- $b$-PEO block copolymer and PAA homopolymer on top of a support membrane and subsequent removal of the PAA homopolymer is a straightforward method to rationally design and fabricate composite ultrafiltration membranes with tunable pore sizes. We demonstrate for the first time that varying the PAA content or polymer concentration of the coating solution leads to membranes with different separation properties and permeabilities in the ultrafiltration range.

Two different types of pores are formed: small pores in the range of $10-40 \mathrm{~nm}$ by microphase separation, and larger pores up to several hundreds of nanometers by macrophase separation. The use of low homopolymer fractions leads to small ordered and relatively monodisperse pores. Increasing the homopolymer content first not only increases the size of the microphase separation pores but also enhances the formation of macrophase separation pores. At higher homopolymer contents $\left(f_{\mathrm{PAA}}>0.15\right)$, the pores formed by microphase separation become smaller and at some point even disappear, because more homopolymers end up in large areas formed by macrophase separation that appear as craters at the surface. This implies that the use of the method described in this article is limited to a certain homopolymer content, and hence pore size, for fabricating monodisperse pores.

The permeability of the composite membranes increases when a lower polymer concentration is used for the coating solution. A lower polymer concentration leads to a thinner top film, hence shorter pores with a lower resistance. In addition, the change of vertical to other orientations of the block copolymer deeper into the film leads to a high change of dead-end pores causing a higher hydraulic resistance. This 
effect is enhanced when the top block copolymer film becomes thicker.

The simple method based on a block copolymer/homopolymer system reported in this article is a promising method to fabricate ultrafiltration membranes. The properties of the membranes can simply be tuned by varying the homopolymer content.

\section{ACKNOWLEDGMENTS}

This work is supported by NanoNextNL, a microtechnology and nanotechnology consortium of the Government of The Netherlands and 130 partners. The authors thank Mark A. Smithers (MESA+ Institute, University of Twente, Enschede, The Netherlands) for the High-Resolution SEM imaging.

\section{REFERENCES AND NOTES}

1 M. A. Shannon, P. W. Bohn, M. Elimelech, J. G. Georgiadis, B. J. Marĩas, A. M. Mayes, Nature 2008, 452, 301-310.

2 E. A. Jackson, M. A. Hillmyer, ACS Nano 2010, 4, 35483553.

3 M. M. Pendergast, E. M. V. Hoek, Energy Environ. Sci. 2011, 4, 1946-1971.

4 J. K. Kim, S. Y. Yang, Y. Lee, Y. Kim, Prog. Polym. Sci. (Oxford) 2010, 35, 1325-1349.

5 F. S. Bates, G. H. Fredrickson, Phys. Today 1999, 52, 32-38.

6 T. Yamamoto, T. Kimura, M. Komura, Y. Suzuki, T. Iyoda, S. Asaoka, H. Nakanishi, Adv. Funct. Mater. 2011, 21, 918-926.

7 S. Y. Yang, I. Ryu, H. Y. Kim, J. K. Kim, S. K. Jang, T. P. Russell, Adv. Mater. 2006, 18, 709-712.

8 S. Y. Yang, J. A. Yang, E. S. Kim, G. Jeon, E. J. Oh, K. Y. Choi, S. K. Hahn, J. K. Kim, ACS Nano 2010, 4, 3817-3822.

9 K. V. Peinemann, V. Abetz, P. F. W. Simon, Nat. Mater. 2007, 6, 992-996.

10 M. Mulder, Basic Principles of Membrane Technology, 2nd ed.; Kluwer Academic Publishers: Dordrecht, 1996.

11 S. Rangou, K. Buhr, V. Filiz, J. I. Clodt, B. Lademann, J. Hahn, A. Jung, V. Abetz, J. Membr. Sci. 2014, 451, 266-275.

12 H. Yu, X. Qiu, S. P. Nunes, K.-V. Peinemann, Angew. Chem. Int. Ed. Engl. 2014, 53, 10072-10076.

13 X. Li, C. A. Fustin, N. Lefèvre, J. F. Gohy, S. D. Feyter, J. D. Baerdemaeker, W. Egger, I. F. J. Vankelecom, J. Mater. Chem. 2010, 20, 4333-4339.

14 S. E. Querelle, E. A. Jackson, E. L. Cussler, M. A. Hillmyer, ACS Appl. Mater. Interfaces 2013, 5, 5044-5050.

15 S. Liu, L. Wang, B. Liu, Y. Song, Polymer 2013, 54, 30653070 .

16 E. A. Jackson, Y. Lee, M. A. Hillmyer, Macromolecules 2013 46, 1484-1491.

17 S. Y. Yang, J. Park, J. Yoon, M. Ree, S. K. Jang, J. K. Kim, Adv. Funct. Mater. 2008, 18, 1371-1377.

18 J. Bolton, T. S. Bailey, J. Rzayev, Nano Lett. 2011, 11, 9981001.

19 T. Thurn-Albrecht, R. Steiner, J. DeRouchey, C. M. Stafford, E. Huang, M. Bal, M. Tuominen, C. J. Hawker, T. P. Russell, Adv. Mater. 2000, 12, 787-791.

20 D. H. Park, Nanotechnology 2007, 18, 355304.
21 K. Koo, H. Ahn, S.-W. Kim, D. Y. Ryu, T. P. Russell, Soft Matter 2013, 9, 9059-9071.

22 U. Jeong, D. Y. Ryu, D. H. Kho, D. H. Lee, J. K. Kim, T. P. Russell, Macromolecules 2003, 36, 3626-3634.

23 U. Jeong, D. Y. Ryu, D. H. Kho, J. K. Kim, J. T. Goldbach, D. H. Kim, T. P. Russell, Adv. Mater. 2004, 16, 533-536.

24 X. Li, S. Zhao, S. Zhang, D. H. Kim, W. Knoll, Langmuir 2007, 23, 6883-6888.

25 E. J. Vriezekolk, E. de Weerd, W. M. de Vos, K. Nijmeijer, J. Polym. Sci., Part B: Polym. Phys. 2014, 52, 1568-1579.

26 W. Lee, X. Zhang, R. M. Briber, Polymer 2010, 51, 23762382.

27 U. Jeong, D. Y. Ryu, J. K. Kim, D. H. Kim, X. Wu, T. P. Russell, Macromolecules 2003, 36, 10126-10129.

28 S. B. Darling, Prog. Polym. Sci. 2007, 32, 1152-1204.

29 R. A. Segalman, Mater. Sci. Eng. R Rep. 2005, 48, 191-226.

30 S. H. Kim, M. J. Misner, L. Yang, O. Gang, B. M. Ocko, T. P. Russell, Macromolecules 2006, 39, 8473-8479.

31 C. Lee, S. H. Kim, T. P. Russell, Macromol. Rapid Commun. 2009, 30, 1674-1678.

32 P. L. Y. Mansky, Science 1997, 275, 1458-1460.

33 R. Guo, E. Kim, J. Gong, S. Choi, S. Ham, D. Y. Ryu, Soft Matter 2011, 7, 6920-6925.

34 D. Y. Ryu, K. Shin, E. Drockenmuller, C. J. Hawker, T. P. Russell, Science 2005, 308, 236-239.

35 J. Bang, J. Bae, P. Löwenhielm, C. Spiessberger, S. A. Given-Beck, T. P. Russell, C. J. Hawker, Adv. Mater. 2007, 19, 4552-4557.

36 Z.-R. Chen, J. A. Kornfield, Polymer 1998, 39, 4679-4699.

37 S. Sakurai, Polymer 2008, 49, 2781-2796.

38 R. J. Albalak, E. L. Thomas, J. Polym. Sci. Part B: Polym. Phys. 1993, 31, 37-46.

39 T. Xu, A. V. Zvelindovsky, G. J. A. Sevink, K. S. Lyakhova, H. Jinnai, T. P. Russell, Macromolecules 2005, 38, 1078810798.

40 V. K. Gupta, R. Krishnamoorti, J. A. Kornfield, S. D. Smith, Macromolecules 1995, 28, 4464-4474.

41 A. Knoll, A. Horvat, K. S. Lyakhova, G. Krausch, G. J. A. Sevink, A. V. Zvelindovsky, R. Magerle, Phys. Rev. Lett. 2002, 89, 035501.

42 G. Kim, M. Libera, Macromolecules 1998, 31, 2569-2577.

43 G. Kim, M. Libera, Macromolecules 1998, 31, 2670-2672.

44 S. H. Kim, M. J. Misner, T. P. Russell, Adv. Mater. 2004, 16, 2119-2123.

45 S. H. Kim, M. J. Misner, T. Xu, M. Kimura, T. P. Russell, Adv. Mater. 2004, 16, 226-231.

46 Z. Q. Lin, D. H. Kim, X. D. Wu, L. Boosahda, D. Stone, L. LaRose, T. P. Russell, Adv. Mater. 2002, 14, 1373-1376.

47 S. Roland, D. Gaspard, R. E. Prud'homme, C. G. Bazuin, Macromolecules 2012, 45, 5463-5476.

48 W. A. Phillip, B. O’Neill, M. Rodwogin, M. A. Hillmyer, E. L. Cussler, ACS Appl. Mater. Interfaces 2010, 2, 847-853.

49 L. Li, P. Szewczykowski, L. D. Clausen, K. M. Hansen, G. E. Jonsson, S. Ndoni, J. Membr. Sci. 2011, 384, 126-135.

50 N. Lefèvre, K. C. Daoulas, M. Müller, J. F. Gohy, C. A. Fustin, Macromolecules 2010, 43, 7734-7743.

51 C. M. Hansen, Hansen Solubility Parameters: A User's Handbook; CRC Press: Boca Raton, 2000.

52 A. Faraone, S. Magazù, G. Maisano, P. Migliardo, E. Tettamanti, V. Villari, J. Chem. Phys 1999, 110, 1801-1806.

JOURNAL OF POLYMER SCIENCE, PART B: POLYMER PHYSICS 2015, 53, 1546-1558 
53 C. Branca, A. Faraone, S. Magazù, G. Maisano, P. Migliardo, V. Villari, J. Mol. Liq. 2000, 87, 21-68.

54 J. D. Le Roux, D. R. Paul, J. Membr. Sci. 1992, 74, 233-252.

55 W. Joo, S. Y. Yang, J. K. Kim, H. Jinnai, Langmuir 2008, 24 12612-12617.

56 B. Nisol, G. Oldenhove, N. Preyat, D. Monteyne, M. Moser, D. Perez-Morga, F. Reniers, Surf. Coat. Technol. 2014, 252, 126-133.
57 A. Asatekin, S. Kang, M. Elimelech, A. M. Mayes, J. Membr. Sci. 2007, 298, 136-146.

58 L. Palacio, C.-C. Ho, A. L. Zydney, Biotechnol. Bioeng. 2002, 79, 260-270.

59 R. Baker, Membrane Technology and Applications, 2nd ed.; Wiley: Chichester, 2004.

60 G. B. van den Berg, C. A. Smolders, Desalination 1990, 77, 101-133. 